\section{A Rapid Method for Screening Sweetpotato Genotypes for Oviposition Stimulants to the Sweetpotato Weevil}

\author{
Ki-Cheol Son \\ Department of Horticulture, University of Georgia, Athens, GA 30602
}

\author{
Ray F. Severson \\ Tobacco Quality and Safety Research Unit, Agricultural Research \\ Service, U.S. Department of Agriculture, Athens, GA 30613
}

\author{
Stanley J. Kays \\ Department of Horticulture, University of Georgia, Athens, GA 30602
}

Additional index words. boehmeryl acetate, triterpene, germplasm, gas chromatography, Ipomoea batatas, Cylas formicarius elegantulus

Abstract. Methodology was developed for the rapid quantitative and qualitative screening of sweetpotato [Ipomoea batatas (L.) Lam.] germplasm for the concentration of the major sweetpotato weevil oviposition stimulant, boehmeryl acetate, and its alcohol, boehmerol. The major surface components were rapidly quantified, using a minimum of plant material. Boehmeryl acetate, present in methylene chloride root extracts, did not degrade when held under normal laboratory conditions for 45 days. Boehmeryl acetate and boehmerol were found only in the outer 1 to $1.2 \mathrm{~mm}$ of periderm and the distribution of the compounds appeared to be relatively uniform over the surface of the root.

Boehmeryl acetate, a kairomone recently identified from sweetpotato roots (Son et al., 1990a), has been shown to stimulate oviposition of the sweetpotato weevil (Nottingham et al., 1987; Wilson et al., 1989). To date, it is the single most important component of the surface compounds that modulate the susceptibility of sweetpotato to the weevil (Wilson et al., 1989). The isolation and purification of boehmeryl acetate has been described (Son et al., 1990 b); however, this technique is laborious, time-consuming, and not suited to the analysis of the many progeny from a breeding program. Development of a rapid sampling and analytical technique for boehmeryl acetate would allow screening of parent lines and progeny from sweetpotato breeding programs for weevil susceptibility. An analytical approach would increase both the precision and number of lines that could be screened for resistance (Kays and Horvat, 1983), In addition, it would allow selecting for weevil resistance in geographical areas where the insect is not present.

The following study was conducted to develop a rapid but precise method for measuring the concentration of boehmeryl acetate and other root surface components in fieldsampled sweetpotatoes. We determined: 1 ) the minimum surface area that could be sampled to give accurate results; 2) differences in the distribution of surface components between proximal and distal ends of the roots; 3 ) differences in the cross-sectional distri-

Received for publication 2 Feb. 1990. The cost of publishing this paper was defrayed in part by the payment of page charges. Under postal regulations, this paper therefore must be hereby marked advertisement solely to indicate this fact. bution of surface components; and 4) the stability of boehmeryl acetate in samples stored for varying intervals under ambient conditions,

'Centennial' sweetpotato roots were harvested in 1988, cured, and stored for 3 months using recommended procedures (Steinbauer and Kushman, 1971). Relatively blemish-free U.S. \#1 roots of about the same shape were removed from storage and allowed to equilibrate to room temperature (21C). Methylene chloride $\left(\mathrm{MeCl}_{2}\right)$ (distilled in glass grade; Burdick and Jackson, Muskegon, Mich.), trimethylsilylimidazol (TMSI), and Tri Sil$\mathrm{Z}$ (TMSI in dry pyridine, $1.5 \mathrm{mEq} / \mathrm{ml}$ ) (Pierce Chemical Co., Rockford, Ill.), and hexacosanol (Analabs, Norfolk, Corm.) were used as received.

Samples were removed from the storage root using a \#14 cork borer $(2.2 \mathrm{~cm}$ i.d.), and the surface was dissected using a razor blade to give a 3-mm-thick slice. Three surface disks $\left(11.4 \mathrm{~cm}^{2}\right)$ were put into a $20-\mathrm{ml}$ scintillation vial containing $10 \mathrm{ml}$ of methylene chloride. Thirty microliters of internal standard solution (hexaconsanol, 0.22 $\mathrm{mg} \cdot \mathrm{ml}^{-1}$ in distilled benzene) was added, the vial sealed with a teflon-lined cap, and ultrasonicated for $8 \mathrm{~min}$ as described by Son et al. (1990a). Disks were removed from the scintillation vial. About $5 \mathrm{ml}$ of distilled water was added to dissolve the sugars, and the water was removed using a pipette. A small amount of $\mathrm{NaSO}_{4}$ was added, depending on the extent of emulsion, and the solution was agitated. A 5-ml portion of the methylene chloride extract was transferred to an 8-ml test tube, dried under a stream of nitrogen, and redissolved in $300 \mu$ l of methylene chloride. Then, $200 \mu \mathrm{l}$ were transferred to a mi- croautosampler vial and the solvent was removed using a stream of nitrogen. Fifty microliters of 3 Tri Sil-Z : 1 TMSI derivatizing reagent was added and the microautosampler vial sealed with a crimp cap. After being heated for $45 \mathrm{~min}$ at $76 \mathrm{C}$, the samples (equivalent to $3.8 \mathrm{~cm}^{2}$ ) were analyzed on a Hewlett-Packard (Palo Alto, Calif.) 5890A reporting gas chromatography [equipped with a 7673A automatic sampler, split-splitless injection port, flame ionization detector (FID), and HP 3393A computing integrator] using a $0.3 \mathrm{~mm}$ i.d. $\times 30 \mathrm{~m}$ thin film SE-54 fused silica column. The temperature was programmed to increase from $140 \mathrm{C}$ after a 2 min hold to $180 \mathrm{C}$ at $8 \mathrm{C} / \mathrm{min}$ and then to $290 \mathrm{C}$ at $4 \mathrm{C} / \mathrm{min}$ with a $10-\mathrm{min}$ postrun hold time. Hydrogen carrier flow rate was $54 \mathrm{~cm} \cdot \mathrm{s}^{-1}$. Injection port and FID temperatures were $250 \mathrm{C}$ and $310 \mathrm{C}$, respectively. Columns were prepared from Hewlett-Packard fused silica tubing according to the procedure of Arrendale et al. (1984). Analysis was done in the splitless injection mode using a 1-min purge activation time.

To ascertain the cross-sectional distribution of boehmeryl acetate, boehmerol, and other surface components, disks were dis-

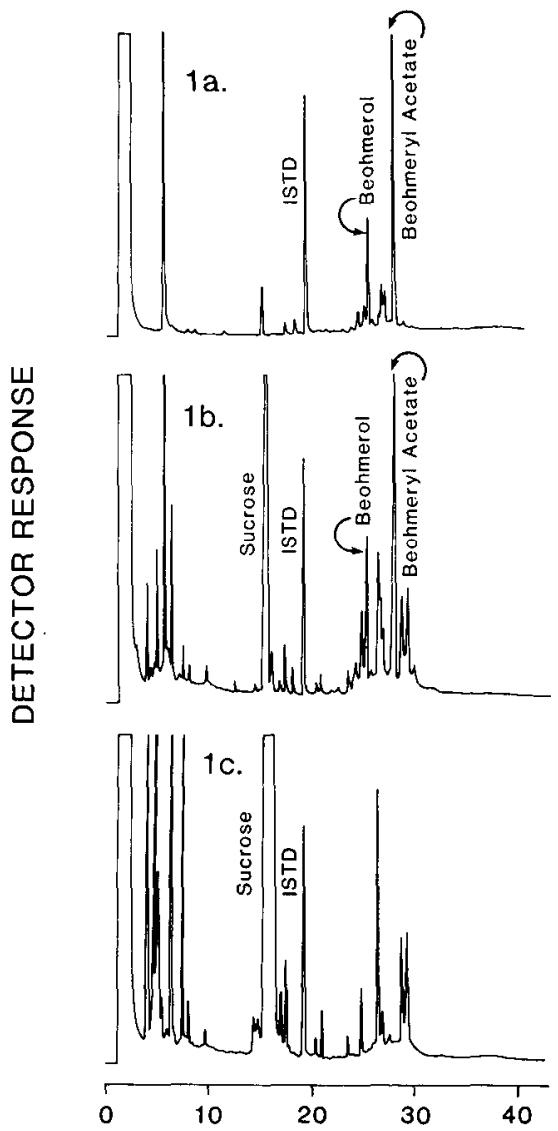

TIME ( MIN )

Fig. 1. Capillary gas chromatograms of silylated 'Centennial' sweetpotato storage root extracts: (a) surface extract of intact roots, (b) periderm disk extract (surface 1 to $1.2 \mathrm{~mm}$ ), and (c) subsurface disk extract (tissue 4 to $5 \mathrm{~mm}$ below the surface). Three replications of five disks taken from the middle of a root were used. 
sected at two depths (surface 1-1.2 mm and 4 to $5 \mathrm{~mm}$ below the surface) from the surface, extracted, and analyzed. The distribution of the compounds over the surface of the roots was determined by sampling at the stem end (proximal), middle, and root end (distal). Stability of boehmeryl acetate in sample extracts was investigated at varying time intervals, i.e., the day of sampling (3 $\mathrm{h}$ after extraction), and 3,15, and 45 days after sampling. Three replicated extracts for each date were left on the laboratory bench (21C), while identical samples were held at - 18C during the experimental period (with exception of the first analysis).

Surface disks displayed similar boehmerol and boehmeryl acetate profiles (Fig. 1b) as surface extracts from intact roots (Fig. 1a), indicating their acceptability as a measure of surface terpene chemistry. A surface area equivalent to $3.8 \mathrm{~cm}^{2}$ (i.e., one disk) was sufficient for quantitative analysis. Thus, the sampled root(s) could be retained for propagation material or other assays and other Ipomoea spp. producing only rudimentary storage roots could be assessed.

Disks whose surface had been dissected indicated that boehmeryl acetate and boehmerol existed only in the surface 1 to 1.2 $\mathrm{mm}$ of the periderm (Fig. 1b), not in the tissue beneath (Fig. 1c). Boehmeryl acetate and boehmerol distribution over the root surface was very uniform, as indicated by an absence of a significant $(P=0.05)$ gradient between the proximal and distal ends. The range was $3.21 \pm 0.43$ to $3.76 \pm 0.18$ $\mu \mathrm{g} \cdot \mathrm{cm}^{-2}$ for boehmeryl acetate and $1.57 \pm$ 0.12 to $1.74 \pm 0.06 \mu \mathrm{g} \cdot \mathrm{cm}^{-2}$ for boehmerol. Thus, the position from which the core is removed from the root during field sampling is not critical.

The concentration of boehmeryl acetate did not change significantly during the 45-day test period. Likewise, we have stored samples at $-18 \mathrm{C}$ for more than 18 months without significant changes in the concentration of boehmeryl acetate. Forty-five days should be sufficient time to move the samples from distant sites to a laboratory with cold-storage facilities and, therefore, make it possible to analyze samples from various breeding programs in a centralized laboratory. Based on the time required for gas chromatographic analysis, using a single instrument equipped with an autoinjector and 20\% instrument down time, 60,000 to 65,000 samples could be analyzed per year.

The method described for sample collection and subsequent analysis will allow chemical analysis of root surface components stimulating weevil oviposition. The technique is accurate, fast, relatively inexpensive, and amenable to assessment of large numbers of genetic crosses.

\section{Literature Cited}

Arrendale, R.F., R.F. Severson, and O.T. Chortyk. 1984. Open split interface for capillary gas chromatograph/mass spectrometry. Anal. Chem. 56:1533-1537.

Kays, S.J. and R.J. Horvat. 1983. Insect resistance and flavor chemistry: Integration into fu- ture breeding programs. In: F.W. Martin (ed.). Breeding new sweet potatoes for the tropics. Amer. Soc. Hort. Sci. Trop. Reg. 27(B):97106.

Nottingham, S.F., D.D. Wilson, R.F. Severson, and S.J. Kays. 1987. Feeding and oviposition preferences of the sweet potato weevil,Cylas formicarius elegantulus, on the outer periderm and exposed inner core of storage roots of selected sweet potato cultivars. Entomol. Expt. Appl. 45:271-275.

Son, K.-C., R.F. Severson, R.F. Arrendale, and S.J. Kays. 1990a. Isolation and characterization of pentacyclic triterpene ovipositional stimulant for the sweet potato weevil from Ipomoea $b a$ - tatas (L.) Lam. J. Agr. Food Chem. 38:134137.

Son, K.-C., R.F. Severson, R.F. Arrendale, and S.J. Kays. 1990b. Surface chemical differences between sweetpotato lines with varying levels of resistance to the sweetpotato weevil. J. Amer. Soc. Hort. Sci. 115:696-699.

Steinbauer, C.E. and L.J. Kushman. 1971. Sweetpotato culture and diseases. U.S. Dept. Agr. Hdbk. 338. Washington, D.C.

Wilson, D.D., K.-C. Son, S.F. Nottingham, R.F. Severson, and S.J. Kays. 1989. Characterization of an oviposition stimulant from the surface of sweet potato Ipomoea batatas storage roots for the sweet potato weevil, Cylas formicarius elegantulus. Entomol. Expt. Appl. 51:71-75. 